\title{
The influence of physical self-perception of female college students participating in Pilates classes on perceived health state and psychological wellbeing
}

\author{
Su Yeon Roh* \\ Department of Exercise Rehabilitation and Welfare, College of Health Science, Gachon University, Incheon, Korea
}

The purpose of this study is to examine the influence of physical self-perception of female college students participating in Pilates on perceived health state and psychological wellbeing. The subjects of this study were 187 female college students participating in Pilates classes in six universities located in Gyeonggi-do. The collected data was analyzed by using SPSS and AMOS 18.0 version. The results are as follows. First, the physical self-perception of female college students participating in Pilates classes affects their perceived health state. Second, the physical self-perception of female college students participating in Pilates classes affects their psychological well-being. Third, the perceived health state of female college students participating in Pilates classes affects their psychological well-being. Fourth, there is a causal relationship among the physical self-perception, perceived health state, and psychological well-being of female college students participating in Pilates classes. In particular, the physical self-perception obtained by the students through their Pilates classes strengthens their psychological well-being through their perceived health state.

Keywords: Pilates, Physical self-perception, Perceived health state, Psychological wellbeing, Female college students

\section{INTRODUCTION}

The industrialization in the wake of the Korean War and the subsequent economic growth had a great impact on various aspects of the South Korean society and played a positive role in improving the quality of life of the individual citizens. Such rapid industrialization also had psychological ramifications for the people, however, such as anxiety or depression. As such, the public is beginning to pay growing attention to the aspects of physical and psychological health to solve the aforementioned problem.

In particular, the South Korean public is paying increasing attention to slow exercises like yoga and Pilates, which emphasize the harmony between the physical and psychological aspects ( $\mathrm{Ko}_{\mathrm{O}}$ and Sung, 2009). In the midst of such rapid changes, the individual interest in physical activity has shifted from competitive physical activities showcasing one's physical excellence or superiority to an entirely different type of physical activity, in which the body

and the mind are being developed in harmony (Roh, 2016a).

Pilates, which was invented in the early 1900s by Joseph H. Pilates of Germany, was created based on the principle of six movements: centering, concentration, control, precision, breath, and flow (Roh, 2016b). According to Roh (2016c), Pilates helps develop a balance between the body posture and the body shape based on mental concentration and restrained movement, by promoting the use of the small muscles that are not normally used, all without requiring significant physical activity. First of all, Pilates plays a positive role in relieving stress, which is a growing issue in modern society, by contributing to a person's psychological stability through meditation in a restricted space (Memmedova, 2015).

Thanks to such physical and psychological effects, Pilates is perceived as a very useful physical activity for college students, who are increasingly struggling with anxiety or depression due to concerns about their academic performance or future employ-

${ }^{*}$ Corresponding author: Su Yeon Roh (iD https://orcid.org/0000-0001-5573-5870 Department of Exercise Rehabilitation and Welfare, College of Health Science, Gachon University, 191 Hambangmoe-ro, Yeonsu-gu, Incheon 21936, Korea Tel: +82-32-820-4254, Fax:+82-32-820-4449, E-mail: rsypilates@naver.com Received: February 21, 2018 / Accepted: March 27, 2018 
ment. Given that in the process of hiring employees equal emphasis is given to appearance and academic performance, participation in Pilates as a college class will offer college students, especially the female ones, an opportunity to perceive the positive abilities of their bodies. As such, Pilates as a college class can play an important role in helping college students form a positive perception of their bodies.

A positive body perception has an important effect on an individual's cognitive health and psychological well-being (Bullo et al., 2015). Baek and Jeong (2006) reported that how individuals perceive their respective bodies has a positive effect on their psychological well-being, including all activities related to physical and mental health as well as healthy eating.

In particular, physical activities like Pilates help individuals perceive their own body positively and make them healthy, thereby improving their psychological well-being, which for many individuals is the touchstone of the quality of their body (Penedo and Dahn, 2005). In other words, cognitive health state and psychological well-being have been reported to be closely related with the physical self-conception formed as a result of physical activity, and the strong correlation among these variables was recently shown to be important in the sports field, such as in Pilates, particularly for physical and psychological development (Scully et al., 1998).

Therefore, it is very timely to analyze the causal relationships among physical self-perception, cognitive health state, and psychological well-being through Pilates activities, which contribute significantly to the harmonious development of physical beauty and psychological stability. Furthermore, it is important to study how psychological well-being affects individual happiness.

The aim of this study was to empirically demonstrate the effect of physical self-perception and perceived health state on the psychological well-being of female college students participating in Pilates classes. Below are the specific research hypotheses.

(a) Does the physical self-perception of female college students participating in Pilates classes affect their perceived health state?

(b) Does the physical self-perception of female college students participating in Pilates classes affect their psychological well-being?

(c) Does perceived health state of female college students participating in Pilates classes affect their psychological well-being?

(d) Is there a causal relationship among the physical self-perception, perceived health state, and psychological well-being of female college students participating in Pilates classes?

\section{MATERIALS AND METHODS}

\section{Study subjects}

For this study, female college students participating in Pilates classes at six universities located in Gyeonggi-do were selected to comprise the study population. Questionnaire copies were distributed to a total of 240 participants using the convenience sampling method, with 198 of them retrieved in the end. Of the collected data, 187 were used for the actual analysis, with the remaining 11 questionnaires that were deemed unreliable due to the absence of entries or due to the presence of double entries excluded from among the samples. The questionnaire was designed to explain the purpose, contents, and methods of the study to the professors currently teaching Pilates at each university. The self-administration method, which prompts the respondents to fill out the questionnaire, was adopted for the survey. Table 1 shows the general characteristics of the study subjects.

\section{Research tools}

To attain the purpose of this study, the survey questions were made to consist of two items on the respondents' demographic characteristics, eight items on the respondents' physical self-perception, four items on the respondents' perceived health state, and 16 items on the respondents' psychological well-being.

First, physical self-perception, which was set as an independent variable in the previous researches conducted by Fox and Corbin (1989), was modified and supplemented based on the purpose of this study. As mentioned earlier, there were eight items on physical self-perception: four on physical attractiveness and four on body image. Each item was scored based on a 5-point Likert scale with "not at all" given 1 point and "very agreeable" given 5 points.

For the mediating variable, the perceived health state variable Table 1. General features of the study subjects

\begin{tabular}{lc}
\hline Variable & No. of subjects (\%) \\
\hline Year of student & \\
1st year & $32(17.1)$ \\
2nd year & $95(50.8)$ \\
3rd year & $33(17.6)$ \\
4th year & $27(14.5)$ \\
Major & \\
Humanities \& social sciences & $31(16.6)$ \\
Sciences & $25(13.4)$ \\
Engineering & $20(10.7)$ \\
Art \& sport & $111(59.3)$
\end{tabular}


developed by Speake et al. (1989) was again modified and supplemented based on the purpose of this study. Perceived health state was a single factor, and there were four items on it, with each item scored based on a 5-point Likert scale where "very unhealthy" was given 1 point and "very healthy" was given 5 points.

For the dependent variable, Psychological Well-Being Scale developed by Ryff (1989) was again modified and supplemented based on the purpose of this study. The psychological wellness questionnaire consisted of 16 items: four on positive interpersonal relationships, four on personal growth, four on life purpose, and four on autonomy.

\section{Validity and reliability of the questionnaire}

To verify the validity and reliability of the survey tools, their contents were reviewed by two professors of sports sociology and psychology. In this process, the author examined the questionnaire items to determine if these clearly and thoroughly explained the variables to be investigated, and reconstructed the items by revising what had been pointed out as flaws in the review process. Exploratory factor analysis (EFA) was used to verify the construction validity of the measurement tool, and the square rotation method was used as a factor rotation method. The initial eigenvalue for factor extraction was set at 1.0 or higher. In addition, any item with a value lower than the factor loading value of 0.4 was removed.

As shown in Table 2, two factors consisting of eight items on physical self-perception were initially extracted from the factor analysis. The factor loadings of physical attractiveness were measured at $0.681-0.821$, and those of body were measured at 0.612 0.724 . The reliability of the physical self-perception value was measured at $0.821-0.756$, confirming the reliability of the ques-

Table 2. Exploratory factor analysis results of physical self-perception

\begin{tabular}{lcc}
\hline Question & Physical attractiveness & Physical self-perception \\
\hline 0.6 & 0.821 & 0.123 \\
0.7 & 0.756 & 0.213 \\
0.8 & 0.723 & 0.157 \\
0.5 & 0.681 & 0.297 \\
0.1 & 0.134 & 0.724 \\
0.2 & 0.254 & 0.711 \\
0.3 & 0.229 & 0.631 \\
0.4 & 0.219 & 0.612 \\
Eigenvalue & 3.257 & 1.312 \\
$\%$ Dispersion & 39.264 & 22.237 \\
Cumulative \% & 39.264 & 61.501 \\
Cronbach $\alpha$ & 0.821 & 0.756 \\
\hline
\end{tabular}

KMO $=0.723 ;$ Chi-square $=812.269 ;$ Sig. $=0.000$. tionnaire.

As seen in Table 3, the factor analysis consisting of four items on perceived health state showed that one factor was extracted, and the factor loadings of perceived health state were measured at 0.811-0.911. The Cronbach alpha of perceived health state was measured at 0.856 , thereby confirming that it was within the reliable levels.

Table 4 shows the EFA results of psychological well-being. In the factor analysis consisting of 16 items on psychological well-being, four factors were extracted after removing four items with a factor loading of less than 0.40 . The results of this study are as follows. First, the factor loadings of positive interpersonal relationships were measured at $0.809-0.852$, those of personal growth were measured at $0.809-0.871$, those of life purpose were

Table 3. Exploratory factor analysis results of perceived health state

\begin{tabular}{lc}
\hline Question & Perceived health state \\
\hline 0.2 & 0.911 \\
0.4 & 0.893 \\
0.3 & 0.871 \\
0.1 & 0.811 \\
Eigenvalue & 3.432 \\
$\%$ Dispersion & 69.291 \\
Cumulative \% & 69.291 \\
Cronbach $\alpha$ & 0.856 \\
\hline
\end{tabular}

KMO =0.720; Chi-square $=612.234 ;$ Sig. $=0.000$.

Table 4. Exploratory factor analysis results of psychological well-being

\begin{tabular}{lcccc}
\hline Question & $\begin{array}{c}\text { Interpersonal } \\
\text { relationship }\end{array}$ & $\begin{array}{c}\text { Personal } \\
\text { growth }\end{array}$ & Life purpose & Autonomy \\
\hline 0.3 & 0.852 & 0.135 & 0.046 & 0.056 \\
0.1 & 0.821 & 0.056 & 0.263 & 0.123 \\
0.2 & 0.819 & 0.135 & 0.074 & 0.211 \\
0.4 & 0.809 & -0.098 & 0.210 & 0.182 \\
0.6 & 0.071 & 0.871 & 0.016 & 0.121 \\
0.7 & 0.056 & 0.826 & 0.108 & 0.109 \\
0.9 & 0.134 & 0.809 & 0.029 & 0.110 \\
0.12 & 0.018 & 0.056 & 0.856 & 0.121 \\
0.10 & 0.156 & 0.131 & 0.791 & 0.112 \\
0.13 & 0.128 & 0.029 & 0.742 & 0.100 \\
0.16 & 0.178 & 0.071 & 0.044 & 0.882 \\
0.14 & 0.162 & 0.129 & 0.126 & 0.856 \\
Eigenvalue & 3.541 & 2.012 & 1.741 & 1.212 \\
$\%$ Dispersion & 32.56 & 15.96 & 13.12 & 10.29 \\
Cumulative \% & 31.21 & 48.06 & 63.29 & 73.46 \\
Cronbach $\alpha$ & 0.849 & 0.826 & 0.777 & 0.739 \\
\hline
\end{tabular}

KMO=0.751; Chi-square= 963.296; Sig. $=0.000$. 
measured at $0.742-0.856$, and those of autonomy were measured at $0.856-0.882$. The Cronbach alpha of psychological well-being was measured at $0.739-0.849$, thereby confirming the reliability of the questionnaire.

\section{Confirmatory factor analysis}

Table 5 shows the results of the confirmatory factor analysis (CFA) that was performed to derive the physical self-perception model, perceived health state model, and psychological well-being measurement model, whose fitness were later verified through the EFA and reliability analysis. For the criterion of CFA, the chisquare value was applied, along with the fitness indices goodnessof-fit index (GFI) (0.90), normed fit index (NFI) (0.90), comparative fit index (CFI) (0.90), and root-mean-square error of approximation (RMSEA) (0.08) (Kim, 2013).

The CFA results showed that physical self-perception was within the acceptable range in terms of the fitness of the measurement model $(\mathrm{GFI}=0.912, \mathrm{NFI}=0.918, \mathrm{CFI}=0.942, \mathrm{RMSEA}=0.047)$ $(\mathrm{GFI}=0.911, \mathrm{NFI}=0.913, \mathrm{CFI}=0.916, \mathrm{RMSEA}=0.039)$. The psychological well-being was also within the acceptable range across the baseline $(\mathrm{GFI}=0.931, \mathrm{NFI}=0.956, \mathrm{CFI}=0.938, \mathrm{RM}$ SEA $=0.041)$.

\section{Investigation procedures and data processing methods}

The data from the collected accomplished questionnaires were entered and analyzed using IBM SPSS ver. 18.0 (IBM Co., Armonk, NY, USA). The statistical significance level was set at $P<0.05$ for

Table 5. Confirmatory factor analysis results

\begin{tabular}{lccccc}
\hline Variable & $\chi^{2}$ & GFI & NFI & CFI & RMSEA \\
\hline Physical self-perception & 213.112 & 0.912 & 0.918 & 0.942 & 0.047 \\
Perceived health state & 318.210 & 0.911 & 0.913 & 0.916 & 0.039 \\
Psychological well-being & 210.159 & 0.931 & 0.956 & 0.938 & 0.041 \\
\hline
\end{tabular}

GFI, goodness-of-fit index; NFl, normed fit index; CFI, comparative fit index; RMSEA, root-mean-square error of approximation. each analysis.

Frequency, reliability, and Pearson correlation analyses were conducted, respectively, to show the general characteristics of the study subjects, and EFA and CFA were each conducted to verify the convergent validity, discriminant validity, and validity of the law. Finally, structural equation model (SEM) analysis was conducted to test the hypothesis of the research models.

\section{RESULTS}

\section{Correlations among the variables}

The Pearson correlation coefficients of the variables were measured before analyzing the relationships among the physical self-perception, perceived health state, and psychological well-being of the female college students participating in Pilates classes in this study.

Table 6 shows the results of the correlation analysis among the factors, which was performed to confirm if the discriminant validity among the factors with single dimensionality was satisfied. The correlation coefficients ranged from 0.119 to 0.553 , far less than 0.800 , the reference coefficient of multicollinearity, indicating that there was no problem in terms of multicollinearity.

\section{Verification of the fitness of the research model}

Table 7 shows the results of the verification of the fitness of the research model. The Tucker-Lewis Index (TLI), CFI, and RMSEA indices were used for this purpose, which are recommended for

Table 7. Goodness of fit of SEM

\begin{tabular}{lcccccc}
\hline Index & $\chi^{2}$ & df & $\chi^{2} / \mathrm{df}$ & CFI & TLI & RMSEA \\
\hline Structure model & 29.369 & 6 & 4.894 & 0.911 & 0.902 & 0.046 \\
Judgment criteria & - & - & $\leq 5$ & $\geq 0.90$ & $\geq 0.90$ & $\leq 0.08$ \\
Results & - & - & Good & Good & Good & Good \\
\hline
\end{tabular}

SEM, structural equation model; df, degree of freedom; $\mathrm{CFI}$, comparative fit index; TLI, normed fit index; RMSEA, root-mean-square error of approximation.

Table 6. Results of the correlation analysis among the variables

\begin{tabular}{lcccccc}
\hline Variable & 1 & 2 & 3 & 4 & 5 & 6 \\
\hline Physical attractiveness & 1 & & & & & \\
Physical self-perception & $0.541^{* *}$ & 1 & & & & \\
Perceived health state & $0.312^{* *}$ & $0.396^{* *}$ & 1 & & & \\
Interpersonal relationships & $0.315^{* *}$ & $0.254^{* *}$ & $0.442^{* *}$ & 1 & & \\
Personal growth & $0.265^{* *}$ & $0.213^{* *}$ & $0.512^{* *}$ & $0.512^{* *}$ & 1 & 1 \\
Life purpose & $0.263^{* *}$ & $0.336^{* *}$ & $0.553^{* *}$ & $0.213^{* *}$ & $0.347^{* *}$ & $0.119^{*}$ \\
Autonomy & $0.336^{* *}$ & $0.198^{*}$ & $0.521^{* *}$ & $0.291^{* *}$ & $0.260^{* *}$ & 1 \\
\hline
\end{tabular}

${ }^{*} P<0.05$. ${ }^{* *} P<0.01$. 
Table 8. Results of hypothesis testing

\begin{tabular}{lccccc}
\hline Path & Estimate & SE & $t$ & Sig. & Result \\
\hline $\begin{array}{l}\text { Physical self-perception } \\
\rightarrow \text { Perceived health state }\end{array}$ & 0.613 & 0.081 & 3.317 & 0.001 & Accept \\
$\begin{array}{l}\text { Perceived health state } \\
\rightarrow \text { Psychological well-being }\end{array}$ & 0.503 & 0.051 & 2.961 & 0.001 & Accept \\
$\begin{array}{l}\text { Physical self-perception } \\
\rightarrow \text { Psychological well-being }\end{array}$ & 0.293 & 0.068 & 1.997 & 0.001 & Accept \\
\hline
\end{tabular}

use in determining the fitness and simplicity of a model (Hong, 2000). The compliance index is interpreted to be acceptable when the TLI and CFI are above 0.90, respectively, and when the RMSEA is below 0.08 . The fitness results of the research model based on the aforementioned criteria are as follows: chi-square value, 29.369; degree of freedom, 6; CFI, 0.911; TLI, 0.902; and RMSEA, 0.046. Therefore, the research model that was used for this study was found to be appropriate.

\section{Results of the analysis of the causal relationships}

The validity of the hypotheses for the research model was verified using the path coefficient because the research model may not support all the set hypotheses even if it is appropriate. The verification results are shown in Table 8 . The results of the analysis of the relationship between the physical self-perception and perceived health state of the female college students participating in Pilates classes in this study showed that the path coefficient between the two factors was $0.613(t=3.317, P<0.001)$, indicating that physical self-perception exerts a positive influence on perceived health state.

Second, the results of the analysis of the relationship between the perceived health state and psychological well-being of the female college students participating in Pilates classes in this study showed that the path coefficient between the two factors was $0.511(t=2.548 ; P<0.001)$, indicating that perceived health state exerts a positive influence on psychological well-being.

Third, the results of the analysis of the relationship between the physical self-perception and psychological well-being of the female college students participating in Pilates classes in this study showed that the path coefficient between the two factors was 0.302 ( $t=1.724 ; P<0.001)$, indicating that physical self-perception exerts a positive influence on psychological well-being.

Fourth, the analysis of the direct and indirect effects according to the path showed that the physical self-perception of the female college students participating in Pilates classes in this study exerted not only a direct $(\beta=0.293)$ but also an indirect $(\beta=0.308)$ effect on their psychological well-being, as shown in Table 9, indi-
Table 9. Analysis results of the mediating effects according to the path

\begin{tabular}{lccc}
\hline Path & Total effect & Direct effect & Indirect effect \\
\hline $\begin{array}{l}\text { Physical self-perception } \\
\rightarrow \text { Perceived health state }\end{array}$ & 0.613 & 0.613 & - \\
$\begin{array}{l}\text { Perceived health state } \\
\rightarrow \text { Psychological well-being }\end{array}$ & 0.503 & 0.503 & - \\
$\begin{array}{l}\text { Physical self-perception } \\
\rightarrow \text { Psychological well-being }\end{array}$ & 0.601 & 0.293 & 0.308 \\
\end{tabular}

cating that the total effect adds up to $\beta=0.601$. As such, physical self-perception was found to have exerted a more indirect effect via perceived health state, which is a mediator variable. In other words, the physical self-perception of female college students participating in Pilates classes is believed to be affecting their psychological well-being via their perceived health state.

\section{DISCUSSION}

The purpose of this study was to provide basic data on the relationships among the physical self-perception, perceived health state, and psychological well-being of female college students participating in Pilates classes. Towards this end, the relationship between these variables was discussed in depth in this study.

In the case of the female college students participating in Pilates classes in this study, the more positive their physical self-perception was, the more positive their perceived health state. Although there have been relatively few studies on the physical self-perception and perceived health state of people participating in Pilates classes, Kim et al. (2011) have shown that various physical activities improve individuals' physical self-perception, thereby making them perceive their health state more positively, a finding that supports the results of this study.

In addition, Lee (2005) stated that dance activities such as Pilates improve a person's physical self-perception. Especially, individuals can have a positive experience with their body through body movement, which is a fundamental characteristic of dance. The results of this study show that physical activities like dance can raise a person's self-confidence in relation to their health state, and can promote happiness. In a similar vein, Asci (2002) reported that university students participating in dance activities form a positive physical self-perception, which again improves their health factors, such as their appearance and level of physical fitness, thereby suggesting that improving one's physical self-confidence by engaging in physical activities is a key to positively improve one's perceived health state.

Therefore, the Pilates teachers should always be aware that the 
provision of a variety of programs designed to improve the students' physical self-perception is key to improving their perceived health state.

Second, the physical self-perception of the female college students participating in Pilates classes in this study was shown to have had a positive effect on their psychological well-being. Specifically, the higher the level of physical self-perception of the female college students participating in the Pilates classes was, the more positive their psychological well-being was. Ferreira and Fox (2008) reported that the higher the physical self-perception and self-esteem of individuals are, the higher their psychological well-being, the reason being that individuals' subjective appraisal of their body can be swayed by their physical management and psychological well-being. Seo and Hah (2004) reported that a positive physical self-perception is a very important factor influencing well-being behavior. Therefore, it should be noted that improving the physical self-perception of the students participating in Pilates classes should be a major consideration in teaching such classes because it can encourage the students to actively recognize their psychological well-being.

Third, the perceived health state of the female college students participating in Pilates classes in this study had a positive effect on their psychological well-being, suggesting that the students who perceive themselves as physical healthy are psychologically healthy as well. Jovic-Vranes et al. (2011) examined the relationship between perceived health state and psychological well-being and found that the higher one's perception of one's health state is, the more positive one's perception of one's interpersonal relationships, personal growth, life purpose, and autonomy will be, thereby supporting the results of this study. Therefore, it should be recognized that constantly emphasizing the health effects of dance in Pilates classes can become a mediator that will encourage the students to engage in activities that are desirable for their psychological well-being.

Fourth, the empirical examination of the causal relationships among the physical self-perception, perceived health state, and psychological well-being of female college students participating in Pilates classes show that the physical self-perception of female college students participating in Pilates classes exerts a positive effect on their psychological well-being through their perceived health state. In other words, the psychological well-being of such female students is reinforced by their physical self-perception, but it is influenced more by how positively they perceive their own health state. In summary, the perceived health state of female college students participating in Pilates classes has been proven in this study to be an important variable mediating their physical self-perception and psychological well-being. Therefore, it should be stressed that the students participating in Pilates classes are engaging in healthy activities, and that Pilates improves their health by helping them pursue psychological well-being.

This study was conducted to investigate the effect of the physical self-perception of female college students participating in Pilates classes on their perceived health state and psychological well-being. Towards this end, female college students participating in Pilates classes at six universities located in Gyeonggi-do were selected to comprise the study population using the convenience sampling method, and a total of 187 accomplished questionnaires were used for the analysis. The data collected as such were then analyzed using the SPSS 18.0 and AMOS 18.0 programs. Frequency analysis, reliability analysis, Pearson's product moment correlation coefficient analysis, EFA, CFA, and SEM analysis were also conducted according to the purpose of this study. The conclusions are shown below.

(a) The physical self-perception of female college students participating in Pilates classes affects their perceived health state.

(b) The physical self-perception of female college students participating in Pilates classes affects their psychological well-being.

(c) The perceived health state of female college students participating in Pilates classes affects their psychological well-being.

(d) There is a causal relationship among the physical self-perception, perceived health state, and psychological well-being of female college students participating in Pilates classes. In particular, the physical self-perception obtained by the students through their Pilates classes strengthens their psychological well-being through their perceived health state.

The results of this study suggest that qualitative researches such as those involving interviews with and observations of the study participants are required to improve the understanding of how $\mathrm{Pi}$ lates teaching can improve the physical self-perception and perceived health state of the participants, and how these positive perceptions can improve their psychological well-being.

\section{CONFLICT OF INTEREST}

No potential conflict of interest relevant to this article was reported.

\section{REFERENCES}

Asci FH. The effects of step dance on physical self-perception of female 
and male university students. Int J Sport Psychol 2002;33:431-442.

Baek E, Jeong W. Determinants of health oriented consumption. J Consump Cult 2006;9:25-48.

Bullo V, Bergamin M, Gobbo S, Sieverdes JC, Zaccaria M, Neunhaeuserer D, Ermolao A. The effects of Pilates exercise training on physical fitness and wellbeing in the elderly: A systematic review for future exercise prescription. Prev Med 2015;75:1-11.

Ferreira JP, Fox KR. Physical self-perceptions and self-esteem in male basketball players with and without disability: a preliminary analysis using the physical self-perception profile. Eur J Adapt Phys Act 2008;1: 35-49.

Fox KR, Corbin CB. The physical self-perception profile: development and preliminary validation. J Sport Exerc Psychol 1989;11:408-430.

Hong SH. The criteria for selecting appropriate fit indices in structural equation modeling and their reationales. Korean J Clin Psychol 2000; 19:161-177.

Jovic-Vranes A, Jankovic J, Vasic V, Jankovic S. Self-perceived health and psychological well-being among Serbian schoolchildren and adolescents: data from national Health Survey. Cent Eur J Med 2011;6:400406.

Kim BK, Lee JH, Kim JR, Jeong BG, Park KS. Associations between self-efficacy, social capital and self-rated health status in healthy individuals. Korean J Health Promot 2011;11:144-153.

Kim J. Structural equation modeling for humor, job satisfaction, job stress and intention to turnover. J Korean Acad Nurs Adm 2013;19:265-272.

Ko K, Sung J. Balance between body and spirit through Pilates. Phil Mov
2009;17:29-42.

Lee J. A study on physical self-concept through dancing education. Korea Sport Res 2005;16:213-222.

Memmedova K. Impact of Pilates on anxiety attention, motivation, cognitive function and achievement of students: structural modeling. Procedia - Soc Behav Sci 2015:186:544-548.

Penedo FJ, Dahn JR. Exercise and well-being: a review of mental and physical health benefits associated with physical activity. Curr Opin Psychiatry 2005;18:189-193.

Roh SY. An exploration of implications for the development of Pilates instructor system through identification of instructors' difficulties. J Exerc Rehabil 2016a;12:355-362.

Roh SY. Effect of a 16-week Pilates exercise program on the ego resiliency and depression in elderly women. J Exerc Rehabil 2016b;12:494-498.

Roh SY. The effect of 12-week Pilates exercises on wellness in the elderly. J Exerc Rehabil 2016c;12:119-123.

Ryff CD. Happiness is everything, or is it? Explorations on the meaning of psychological well-being. J Pers Soc Psychol 1989;57:1067-1081.

Scully D, Kremer J, Meade MM, Graham R, Dudgeon K. Physical exercise and psychological well being: a critical review. Br J Sports Med 1998; 32:111-120.

Seo HM, Hah YS. A study of factors influencing on health promoting lifestyle in the elderly: application of pender's health promotion model. J Korean Acad Nurs 2004;34:1288-1297.

Speake DL, Cowart ME, Pellet K. Health perceptions and lifestyles of the elderly. Res Nurs Health 1989;12:93-100. 